\title{
THE FEASIBILITY EVALUATION OF LAND USE CHANGE DETECTION USING GAOFEN-3 DATA
}

\author{
Guoman Huang ${ }^{1,2}$, Yue SUN ${ }^{1,2, *}$, Zheng Zhao ${ }^{2}$ \\ ${ }^{1}$ College of Geomatics, Shandong University of Science and Technology, Qingdao 266590, China \\ ${ }^{2}$ Key Laboratory of Geo-Informatics of State Bureau of Surveying and Mapping, Chinese Academy of Surveying and Mapping, \\ Beijing 100830, China - (huang.guoman, superyue926, zhengzhaochina)@163.com
}

\section{Commission III, ICWG III/IVb}

KEY WORDS: GaoFen-3, Change Detection, Land Use, Polarimetric SAR, High-resolution, Quality Evaluation

\begin{abstract}
:
GaoFen-3(GF-3) satellite, is the first C band and multi-polarimetric Synthetic Aperture Radar (SAR) satellite in China. In order to explore the feasibility of GF-3 satellite in remote sensing interpretation and land-use remote sensing change detection, taking Guangzhou, China as a study area, the full polarimetric image of GF-3 satellite with $8 \mathrm{~m}$ resolution of two temporal as the data source. Firstly, the image is pre-processed by orthorectification, image registration and mosaic, and the land-use remote sensing digital orthophoto map (DOM) in 2017 is made according to the each county. Then the classification analysis and judgment of ground objects on the image are carried out by means of ArcGIS combining with the auxiliary data and using artificial visual interpretation, to determine the area of changes and the category of change objects. According to the unified change information extraction principle to extract change areas. Finally, the change detection results are compared with $3 \mathrm{~m}$ resolution TerraSAR-X data and $2 \mathrm{~m}$ resolution multi-spectral image, and the accuracy is evaluated. Experimental results show that the accuracy of the GF-3 data is over $75 \%$ in detecting the change of ground objects, and the detection capability of new filling soil is better than that of TerraSAR$\mathrm{X}$ data, verify the detection and monitoring capability of GF-3 data to the change information extraction, also, it shows that GF-3 can provide effective data support for the remote sensing detection of land resources.
\end{abstract}

\section{INTRODUCTION}

With the continuous improvement of SAR sensor technology, high-resolution imaging technology and data processing technology, the use of remote sensing image to monitor land cover and object changes has gradually become a hot issue in remote sensing applications. SAR has all-day, all-weather, large-range, long-term and periodic earth observation capabilities, especially in areas where cloud cover and multispectral image acquisition data are difficult to obtain, SAR data can provide effective data support for remote sensing detection, so as to ensure the continuity of remote sensing detection.

Change detection is the process of identifying the state change of the objects or phenomena by observing in many times (SINGH, 1989). Automatic and semi-automatic multi-temporal remote sensing images change detection technology has been widely used in land survey, urban research, ecosystem monitoring, disaster monitoring and assessment, military reconnaissance and other applications (LI et al, 2017; LI et al, 2016; HU et al, 2013; SONG et al, 2014; VOGELMANN et al, 2011; ZWLINSKI et al, 2014). Our government attaches great importance to the application of remote sensing change detection technology in the monitoring of geographical conditions. Since 2010, the Ministry of Land and Resources has been carrying out the national land remote sensing detection work every year, and using the multi-temporal remote sensing image change detection technology to continuously update the results of the national land survey (Ministry of Land and Resources of the People's Republic of China, 2010).
The GaoFen-3(GF-3) satellite is one of the research and development projects of China's national scientific and technological major project "High-resolution Earth Observation Series of Major Special Projects" (ZHANG, 2017). It is also China's first C-band multi-polarization high-resolution SAR satellite with 12 imaging modes, and it is the SAR satellite with the largest imaging mode in the world at present. The GF-3 satellite are characterized by high resolution, large imaging breadth, high radiation accuracy, multiple imaging modes and long-time work, enabling surveillance and monitoring of global ocean and land information by both all-day and all-weather (ZHANG, 2017). The successful launch of GF-3 satellite has filled the gap of remote sensing data of civil autonomous highresolution multi-polarization SAR in China and has become an important technical support for the implementation of marine exploitation, monitoring of land environmental resources and disaster prevention and mitigation in China (LIVINGSTONE et al, 2006).

In this paper, GF-3 data are used to remote sensing image interpretation and change detection in some regions of Guangzhou, and the feasibility of GF-3 data in the application of surface features change detection is explored. By means of orthographic, registration, mosaic and cropping of GF-3 full polarimetric images with two temporal resolution of $8 \mathrm{~m}$, a remote sensing image of land use in 2017 is produced in county units. Then by means of ArcGIS, the spatial superposition and contrast analysis are carried out, compared with the 2016 annual land-use remote sensing image, and according to the unified change information extraction principle, the new change area is

\footnotetext{
* Corresponding author at: College of Geomatics, Shandong University of Science and Technology, Qingdao.

E-mail address: superyue926@163.com.
} 
extracted by using the information discovery and extraction method based on man-machine interaction. Finally, statistical analysis, spatial analysis, mathematical model and other methods are adopted and GF-3 data change detection results are compared with $3 \mathrm{~m}$ resolution TerraSAR-X data and $2 \mathrm{~m}$

\begin{tabular}{ccl}
\hline Name & Code & \multicolumn{1}{c}{ Illustration } \\
\hline $\begin{array}{c}\text { New linear objects } \\
\begin{array}{c}\text { New buildings } \\
\text { (structures) }\end{array}\end{array}$ & 11 & $\begin{array}{l}\text { Refers to new linear features such as roads, railways, ditches, etc (including road hardening). } \\
\text { Refers to the new residential land, industrial and mining storage land, public management } \\
\text { and public service land, special land and so on. }\end{array}$ \\
New filling soil & 13 & $\begin{array}{l}\text { It is located in a large-scale concentrated development area, formed the internal road } \\
\text { network, surrounding construction land under construction and both sides of roads for } \\
\text { construction land. }\end{array}$ \\
$\begin{array}{c}\text { Suspected new } \\
\text { change objects }\end{array}$ & 2 & $\begin{array}{l}\text { As a result of the image recognition ability and the object itself spectral characteristics, } \\
\text { building state and scope and other reasons cannot determine. }\end{array}$ \\
\hline
\end{tabular}

resolution multi-spectral change detection results of comparative analysis and precision evaluation, aiming to analyse the feasibility of GF-3 satellite in land-use remote sensing change detection.

Table 1. Code and description of change information

\section{PRINCIPLES AND METHODS}

The experiment mainly explores the feasibility of GF-3 data to detection the change of new objects, with emphasis on the detection of changes in new buildings (structures), new linear objects, new filling soil, and suspected new change objects (see Table 1).

The process of obtaining high-resolution remote sensing images of two temporal in the same area, and obtaining information on the changes of surface feature based on the differences between the images is roughly divided into five steps (Figure 2): (1) To perform data pre-processing on format conversion, radiation correction, orthorectification, image mosaic, and image cropping of GF-3 data in two temporal, (2) Extract the two temporal DOM structure the difference image and draw the outline of the change region, (3) Combine the basic data to determine the type of change region, (4) New change region sorting and statistics; (5) Results comparison analysis and accuracy evaluation of GF-3 data and reference data.

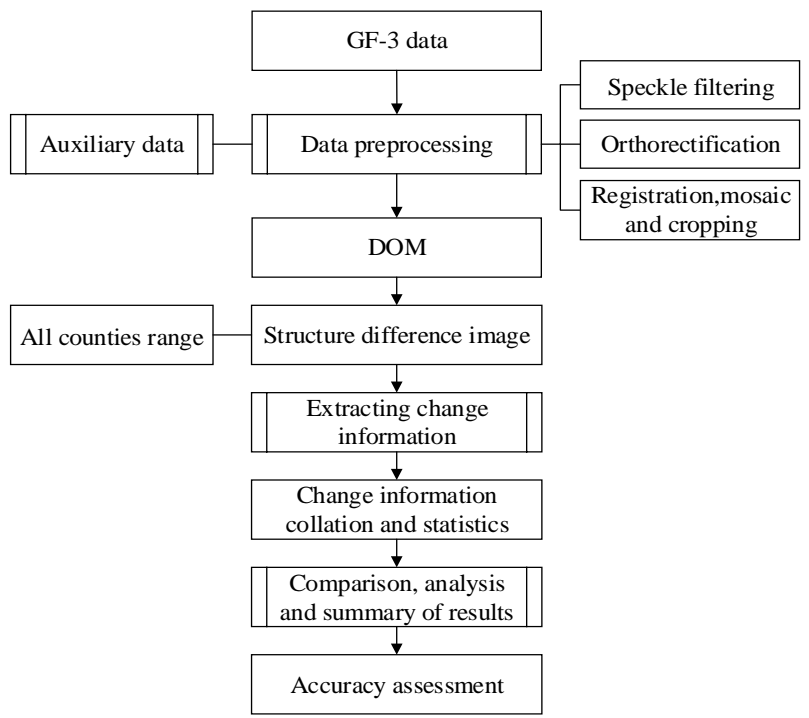

Figure 2. Flowchart of GF-3 change information extraction

\subsection{Orthorectification}

During the imaging process, the satellite is affected by many factors such as atmospheric refraction, surface curvature and topographic relief, which results in geometric distortion of the image, the aim of orthorectification is to eliminate the influence of geometric distortion and correlate the original image pixel location to the real space location of the surface (SUN, 2013).

Therefore, in order to accurately detection the change of ground objects in the two temporal experimental area in Guangzhou, it is necessary to geometric correction of each image, obtain the uniform distribution of the ground point with obvious characteristics as the control point, and realize the registration of multi-temporal remote sensing image. In this experiment, using rational polynomial coefficients (RPC) to orthorectify the GF-3 data.

RPC also known as the rational function model (RFM), is a general imaging geometric model that achieves precision consistent with the rigorous imaging model, has good interpolation characteristics and continuity, the form is simple and independent of the sensor platform, and is a widely used geometric model of high resolution satellites (WU et al, 2004; ZHANG et al, 2008; ZHU et al, 2004). It expresses the image point coordinate $(r, c)$ as the polynomial ratio of the corresponding ground point space coordinate $(\mathrm{X}, \mathrm{Y}, \mathrm{Z})$ as an independent variable (WANG, 2014).

$$
r_{n}=\frac{P_{1}\left(X_{n}, Y_{n}, Z_{n}\right)}{P_{2}\left(X_{n}, Y_{n}, Z_{n}\right)} ; c_{n}=\frac{P_{3}\left(X_{n}, Y_{n}, Z_{n}\right)}{P_{4}\left(X_{n}, Y_{n}, Z_{n}\right)}
$$

Here, $\left(X_{n}, Y_{n}, Z_{n}\right)$ and $\left(r_{n}, c_{n}\right)$ are regularized ground coordinates and image coordinates respectively, for $\mathrm{Pi}\left(\mathrm{X}_{\mathrm{n}}, \mathrm{Y}_{\mathrm{n}}\right.$, $\mathrm{Z}_{\mathrm{n}}$ ) is ordinary polynomial, taking a 3rd-degree polynomial as an example, in the form of :

$$
\begin{aligned}
& P_{i}\left(X_{n}, Y_{n}, Z_{n}\right)=a_{0}+a_{1} Y_{n}+a_{2} X_{n}+a_{3} Z_{n}+a_{4} X_{n} Y_{n}+a_{5} Y_{n} Z+ \\
& a_{6} X_{n} Z_{n}+a_{7} Y_{n}^{2}+a_{8} X_{n}^{2}+a_{9} Z_{n}^{2}+a_{10} X_{n} Y_{n} Z_{n}+a_{11} Y_{n}^{3}+a_{12} Y_{n} X_{n}^{2}+ \\
& a_{13} Y_{n} Z^{2}+a_{14} Y_{n}^{2} X_{n}+a_{15} X_{n}^{3}+a_{16} X_{n} Z_{n}^{2}+a_{17} Y_{n}^{2} Z_{n}+a_{18} X_{n}{ }^{2} Z_{n}+a_{19} Z_{n}^{3}
\end{aligned}
$$

Where, $a_{0}, a_{1}, a_{2}, \cdots, a_{19}$ are parameters for RPC.

After orthorectification, the DOM of every county is mosaic and clip to generate 2017 land-use remote sensing image, and compared with the multi-spectral orthophoto image, using the ArcGIS layer superimposed visual inspection, using the method of "Swipe" analysis found that the image of a better match, 
buildings, roads, water and other no obvious deviation, positioning accuracy is higher, the result is satisfactory. The corrected images are shown in Figure 3.

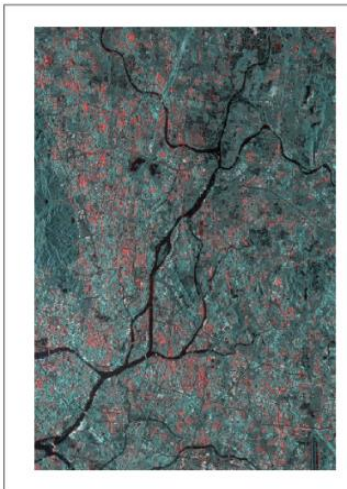

(a) Original GF-3 image

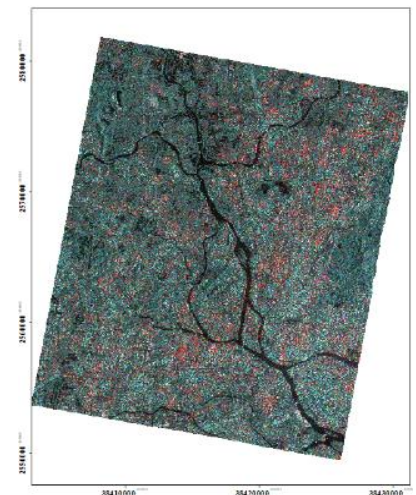

(b) Orthorectification result rectification local image

\subsection{Change Information Extraction}

The extraction of change information plays a vital role in detection the results of land cover change, the discovery of change information is divided into automated and semiautomatic methods. Automated methods include threshold method, region growth method, clustering method, and semiautomatic method, that is, man-machine interaction (HUANG et al, 2004). However, either method is highly dependent on the quality and difference of the two images. By means of fully automatic identification cannot identify the change information accurately and reliably. Therefore, in the actual production, the artificial interpretation is still an important way to extract change information.

This paper uses the method of artificial visual interpretation to extract change information of new objects in Guangzhou. With the help of ArcGIS, determine the areas and types of change based on SAR interpretation experience. Because GF-3 satellite is side-view imaging, the image will have the phenomenon of foreshortening, layover, shadow and so on, in these anamorphic regions, we use the method of combining the original image to judge the area of change, and then delineation the change area in the corresponding position of GF-3 image. Using DOM in the post-temporal, when the resolution of the image is low or the feature of the ground object is not obvious, delineation the boundary of new structures or the trace of moving earth on the ground. In addition, all areas of change are outlined by face shape element, including linear features such as roads and railways. For segmented construction of linear features, only delineation the areas actually completed and under construction, while determining the areas of change, combining the basic data and the characteristics of change objects of the two temporal GF-3 images, four types of change objects are identified, as shown in Figure 4.

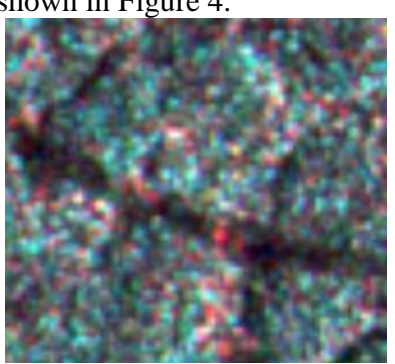

(a) Original image

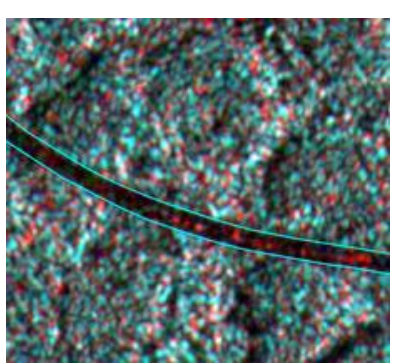

(b) New linear object (11)

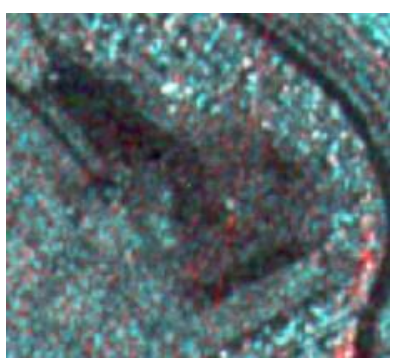

(c) Original image

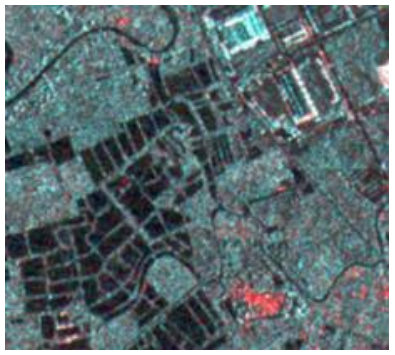

(e) Original image

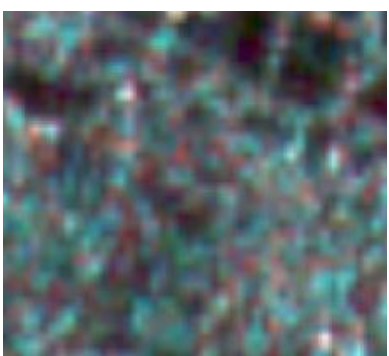

(g) Original image (h) Suspected new change object (2) Figure 4. Schematic diagram of typical surface features change information extraction

\section{RESULTS AND ANALYSIS}

\subsection{Test data}

Test data includes GF-3 data, TerraSAR-X data, multi-spectral images, and corresponding auxiliary data over the Guangdong Guangzhou. The region has complete major landforms that cover the plains, hills and mountains, as well as geographical coordinates of $112^{\circ} 57^{\prime}-114^{\circ} 3^{\prime} \mathrm{E}, 22^{\circ} 26^{\prime}-23^{\circ} 56^{\prime} \mathrm{N}$, under the jurisdiction of 12 municipal districts, respectively, Liwan District, Yuexiu District, Haizhu District, Tianhe District, Baiyun District, Huangpu District, Panyu District, Huadu District, Nansha District, Luogang District, Conghua District, the total area is about $7249.4 \mathrm{~km}^{2}$.

The imaging mode of GF-3 data is quad-polarization stripe 1 (QPSI) mode, product level for geographical reference products of single-look complex (SLC), resolution of $8 \mathrm{~m}$, the pretemporal has acquired 20 images, covering 12 districts in Guangzhou, covering area of about $6567.4 \mathrm{~km}^{2}$, a total of 15 images were obtained in post-temporal, including 10 districts (excluding Liwan District and Yuexiu District), covering area of about $3941.1 \mathrm{~km}^{2}$. The experimental study area is the overlapping area of two temporal images, which is about 3745.4 $\mathrm{km}^{2}$, accounting for $51.7 \%$ of the total area of Guangzhou. Figure 5 displays the study area over the Guangzhou field. 


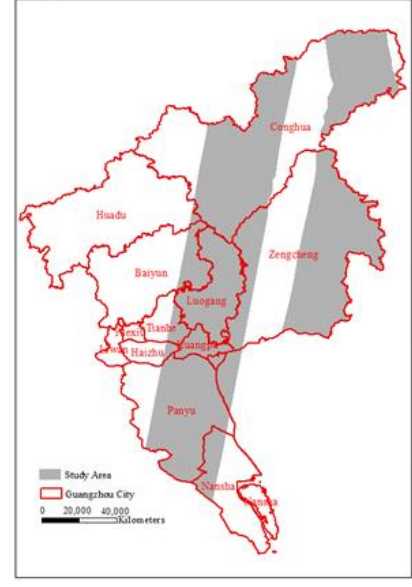

Figure 5. Sketch maps of experimentation area

TerraSAR-X data and multi-spectral image as the reference data. Among them, the ground resolution of the TerraSAR-X data is $3 \mathrm{~m}$, the polarization mode is $\mathrm{HH}$. The imaging satellite of multi-spectral image is SPOT6, which fuses the panchromatic image with multi-spectral image to produce $2 \mathrm{~m}$ resolution image. The availability of data is detailed in Table 6 .

\begin{tabular}{cccc}
\hline Data & $\begin{array}{c}\text { Resolution } \\
(\mathrm{m})\end{array}$ & \multicolumn{2}{c}{ Acquisition time } \\
& \multirow{2}{*}{ Pre-temporal } & Post-temporal \\
\hline \multirow{2}{*}{ GF-3 } & 8 & $2016 / 12 / 16-$ & $2017 / 08 / 05-$ \\
& & $2017 / 04 / 03$ & $2017 / 09 / 20$ \\
TerraSAR-X & 3 & $2016 / 12 / 23-$ & $2017 / 09 / 02-$ \\
& & $2017 / 01 / 14$ & $2017 / 09 / 28$ \\
Multi-spectral & 2 & $2016 / 09 / 14-$ & $2017 / 04 / 01-$ \\
& & $2016 / 12 / 10$ & $2017 / 09 / 28$ \\
\hline
\end{tabular}

Table 6. List of data acquisition

Auxiliary data include: 2016 annual change survey and verification project of remote sensing monitoring results base map, construction land data and Guangzhou DEM data.

\subsection{Experimental results and analysis}

In order to verify the ability of the GF-3 data to extract change information, the change detection results of the GF-3 image and the change detection results of the reference data are compared with some regions in Guangzhou. Through the collation and analysis of the change areas, the change number and area of the four types of change objects are shown in Table 7.

As can be seen from Table 7, the total number of change objects extracted from the GF-3 data is 297 , with a total area of 983 ha, of which the number of 12 accounts for the most, is $38.1 \%$, and the largest area for 13, accounting for $41.4 \%$ of the total area. TerraSAR-X image detected a total of 351 new ground objects with a total area of 1012.4 ha, of which 12 accounted for the largest number of $40.7 \%, 13$ is the largest area, accounting for $34.6 \%$ of the total area. The total number of change information extracted by multi-spectral image detection is 430 , with a total area of 1143 ha, with 12 of the maximum number is $37.9 \%$, and 11 for the largest area is $36.5 \%$.

From Table 7, it can be found that 12 of the three data extracted are the largest number of change objects, for 13, the change detection using GF-3 data is better than TerraSAR-X data, indicating that GF-3 data is more sensitive to the change of 13, and the extraction effect is better, TerraSAR-X data and multispectral image are significantly better at detecting 11 and 12 than GF-3 data.

The statistics of the number and area of change objects detected in each county are shown in Figure 8, among which Luogang and Zengcheng have the largest number of change information, and Zengcheng has the largest area of change objects.

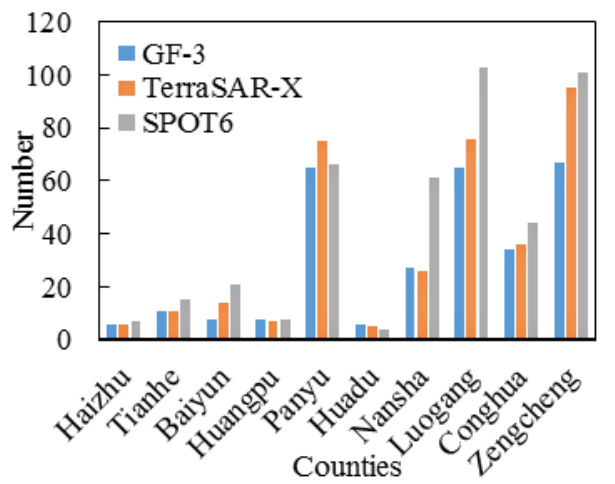

(a) Statistics of the number of new objects

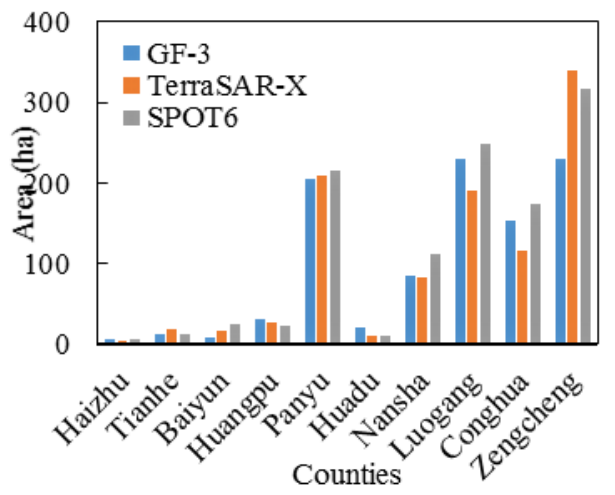

(b) Statistics of the area of new objects

Figure 8. Statistical results of change detection for three groups of images in each county

In order to further compare the change information extracted from GF-3 data and reference data, we divided the extracted change objects into three classes according to area, that is, area less than or equal to 0.3 ha for I, area between 0.3 ha and 0.6 ha for II and area greater than 0.6 ha for III. Then compare the area grading of change objects, as shown in Figure 9.

\begin{tabular}{cccccccccccc}
\hline \multirow{2}{*}{ Data source } & \multicolumn{2}{c}{ Total } & \multicolumn{2}{c}{11} & \multicolumn{2}{c}{12} & \multicolumn{2}{c}{13} & \multicolumn{2}{c}{2} \\
& Sum & Area & Number & Area & Number & Area & Number & Area & Number & Area \\
\hline GF-3 & 297 & 983 & 60 & 270.4 & 113 & 263.1 & 91 & 407.3 & 33 & 42.2 \\
TerraSAR-X & 351 & 1012.4 & 94 & 290.7 & 143 & 314.9 & 87 & 349.8 & 27 & 57 \\
Multi-spectral & 430 & 1143 & 148 & 417.6 & 163 & 315 & 115 & 406.9 & 4 & 3.5 \\
\hline
\end{tabular}

Table 7. Statistics of the number and area of the four types of change objects (Area Unit: ha) 


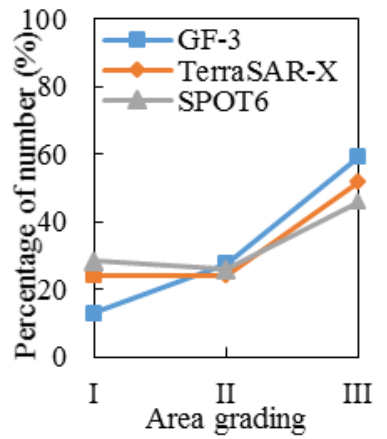

(a) Number ratio

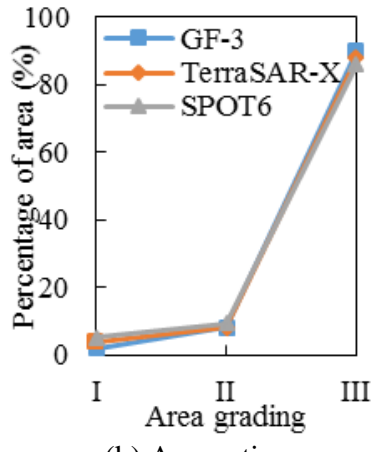

(b) Area ratio

Figure 9. Comparison of area grading between GF-3 data and reference data

Figure 9 depicts the trend of area grading of GF-3 data, TerraSAR-X data and multi-spectral image, from (a) know that the GF-3 data and TerraSAR-X data area grading change trend is the same. Compared to the reference data, changed area in whole scene is relatively too small, weak detection capacity for GF-3 data, all three kinds of data have a good effect on detecting the changing ground objects with large area. From (b), it can be seen that the three data have the same area ratio trend for the area grading of the extracted change features, that is, more than 0.6 ha of the area extracted the most, 0.3 ha to 0.6 ha between the second, less than or equal to 0.3 ha extracted to the least area, which also shows that the detection effect is best for the features with larger change area.

\section{ACCURACY EVALUATION}

In order to compare and evaluate the accuracy of change detection, the change detection results of GF-3 data and TerraSAR-X data, multi-spectral image were compared with four feature types. The evaluation process is mainly involves spatially superimposing the results of GF-3 image extraction with the vector data of TerraSAR-X data and multi-spectral image extraction results, and compare the change feature of the experimental area in different vector layers one by one, to deal with and sort out the different regional inconsistency and dislocation caused by the difference of the resolution, on this basis, statistics of the number and type of ground objects above 0.3 ha in a changing region, and based on the statistical results, we make a centralized analysis of the differences in information about changes between GF-3 and TerraSAR-X, multi-spectral image (Table 10-11).

\begin{tabular}{cccccc}
\hline Reference data & Intersection & $\begin{array}{c}\text { Inconsistent of } \\
\text { temporal }\end{array}$ & $\begin{array}{c}\text { Reference data } \\
\text { omitted extract }\end{array}$ & $\begin{array}{c}\text { GF-3 inaccurate } \\
\text { extract }\end{array}$ & Other reason \\
\hline TerraSAR-X & 236 & 13 & 39 & 9 & 0 \\
Multi-spectral & 224 & 36 & 23 & 12 & 2 \\
\hline \multicolumn{7}{c}{ Table 10. Differential Analysis of GF-3 data and reference data } \\
\hline Data & Reference data & Intersection & $\begin{array}{c}\text { Inconsistent of } \\
\text { temporal }\end{array}$ & $\begin{array}{c}\text { GF-3 omitted } \\
\text { extract }\end{array}$ & $\begin{array}{c}\text { Reference data } \\
\text { inaccurate extract }\end{array}$ \\
\hline TerraSAR-X & \multirow{2}{*}{ GF-3 } & 252 & 19 & 59 & 21 \\
Multi-spectral & & 255 & 78 & 95 & 2 \\
\hline
\end{tabular}

Table 11. Differential Analysis of reference data and GF-3 data

The quantitative evaluation index of the change detection result is of practical significance for evaluating the change detection method, analyzing the trend of the change of ground objects, and providing decision support. The calculation method used in this paper is as follows: the truth value of the change information extracted by GF-3 is the difference between the total number extracted and the number of inaccurate extracted by GF-3, the truth value of the actual change information in the region should be the sum of the true value extracted by GF-3 and the number of GF-3 omitted extraction. Methods in this paper can be effectively used for GF-3 to detect the accuracy of change information, and also eliminates the reason of temporal and the number of inaccurate and omitted extraction of reference data, and the result is closest to the accuracy rate of the change information extracted by GF- 3 .

The accuracy of GF-3 data change information extraction is calculated as follows:

Accuracy $=\frac{\text { Total of extract }- \text { Total of inaccurate extract }}{\text { Total of extract }- \text { Total of inaccurate extract }+ \text { Total number of omitted extract }} \times 100 \%$

Substituting the corresponding value in formula (3) to:

\begin{tabular}{ccc}
\hline \multirow{2}{*}{ Reference data } & \multicolumn{2}{c}{ Accuracy of GF-3 } \\
\cline { 2 - 3 } & Number & Area \\
\hline TerraSAR-X & $82.99 \%$ & $90.27 \%$ \\
Multi-spectral & $75.00 \%$ & $88.77 \%$ \\
\hline \multicolumn{2}{c}{ Table 12. Change detection accuracy of GF-3 data }
\end{tabular}

As GF-3 images are characterized by foreshortening, layover, radar shadow and other phenomena are more obvious in mountainous areas, which bring difficulties to image interpretation of the changing region, Because the phenomena of foreshortening, layover, radar shadow, which are unique to GF-3 images, are more obvious in mountain areas, they make it difficult for image interpretation to change areas, and there is subjectivity in artificial visual interpretation, leading to some change information was inaccurate or omitted extraction, the main reasons are summarized as follows:

(1) The brightness changes of paddy fields caused by water quantity and the state of plant growth in regular farmland with two temporal were mistaken as the change information. 
(2) Compared to multi-spectral image, GF-3 data and TerraSAR-X data are less capable of detecting similar material changes such as road hardening, and the presence of gravel on the road surface, or road moisture, can affect road imaging on SAR images.

(3) The new filling soil shows that the vegetation becomes bare soil on the multi-spectral image, and the hue changes intuitively, but tiles that are only reflected as unevenly distributed in light and shade on TerraSAR-X images, sometimes the post-temporal image will become bright, sometimes the brightness of the two temporal is not much different, hence, only by the brightness of the changes, the naked eye is more difficult to judge the new filling soil. In addition, the change of soil moisture content, vegetation cover on the land, ascending and descending and different angles may cause the change of brightness, so it is easy to cause the inaccurate and omitted extraction of such ground objects.

(4) Suspected new change objects due to the two temporal images of the hue difference is not obvious and image noise and imaging uncertainty factors, cannot judge what type of change information, and the sensitivity of GF-3 and TerraSAR-X to the change of surface material is not high, and it is easy to make such inaccurate and omitted extraction.

\section{CONCLUSION}

The experimental study on the application of GF-3 data to detection ability of change information in Guangzhou shows that:

(1) The experimental results show that the change detection accuracy of GF-3 image with $8 \mathrm{~m}$ resolution can reach more than $75 \%$, which shows that the recognition capability of GF-3 satellite with $8 \mathrm{~m}$ resolution and the image interpretation capability of operators meet the needs of remote sensing detection, and the feasibility of applying GF-3 data to land use change detection by remote sensing is verified.

(2) Compared with TerraSAR-X data with $3 \mathrm{~m}$ resolution, GF-3 data is more sensitive to the change of new bulldozing, and the extraction effect is better.

(3) Buildings can generate strong echoes on GF-3 images, showing a bright, flaky, blocky shape with clear outlines. Through the GF-3 data to extract the change information of the new ground objects, from the experimental results show that GF-3 data and TerraSAR-X data extraction of the change information increases as the increase in area, the accuracy of change information extraction is higher.

(4) Due to the limited availability of data, this paper fails to perform a comparative analysis between $3 \mathrm{~m}$ resolution GF-3 data and TerraSAR-X data, but $8 \mathrm{~m}$ resolution GF-3 data is feasible for land use remote sensing monitoring.

(5) The working results of the experimental methods depend to a great extent on the experience value and the degree of carefulness of the operators, geometric correction, image fusion, image mosaic, change information extraction, and each step is interlocked, the processing of the previous step affects the latter step, especially in the process of change information extraction. How to reduce manual participation, and how to strengthen automation or semi-automation is still a problem that we need to continue to explore.

(6) Due to the unique side-view imaging of SAR, the visual interpretation of SAR image is very different from that of multispectral images. Subsequent research will improve the accuracy of SAR change detection to a certain extent by establishing sample sets of typical features or region of interest.

\section{ACKNOWLEDGEMENT}

This work was supported in part by the Basic Plan of Science and Technology of Surveying and Mapping (NO.2018KJ0103).

\section{REFERENCES}

LI H.X., XIAO P.F., FENG X.Z., et al., 2017. Using Land Long-term Data Records to Map Land Cover Changes in China over 1981-2010. IEEE Journal of Selected Topics in Applied Earth Observations and Remote Sensing, 10 (4), pp. 1372-1389.

LIVINGSTONE C E, SIKANETA I, GIERULL C, et al., 2006. RADARSAT-2 System and Mode Description. Ottawa: Deference Research and Development Canada.

LI Z.B., SHI W.Z., MYINT S W, et al., 2016. Semi-automated Landslide Inventory Mapping from Bitemporal Aerial Photographs Using Change Detection and Level Set Method. Remote Sensing of Environment, (175), pp. 215-230.

Ministry of Land and Resources of the People's Republic of China, 2010. The Notice for National Land-use Change Survey and Remote Sensing Monitoring from Ministry of Land and Resources in 2010. Beijing: Ministry of Land and Resources.

HU J.R., ZHANG Y.Z., 2013. Seasonal Change of Land-use/ Land-cover (LULC) Detection Using MODIS Data in Rapid Urbanization Regions: A Case Study of the Pearl River Delta Region (China). IEEE Journal of Selected Topics in Applied Earth Observations and Remote Sensing, 6 (4), pp. 1913-1920.

HUANG G.M., GUO J.K., ZHAO Z., 2004. Algorithms and experiment on SAR image orthorectification based on polynomial rectification. Science of Surveying and Mapping, 29 (6), pp. 27-30.

SINGH A, 1989. Digital Change Detection Techniques Using Remotely-sensed Data. International Journal of Remote Sensing, 10 (6), pp. 989-1003.

SONG C.Q., HUANG B., KE L.H., et al., 2014. Remote Sensing of Alpine Lake Water Environment Changes on the Tibetan Plateau and Surroundings: A Review. ISPRS Journal of Photogrammetry and Remote Sensing, (92), pp. 26-37.

SUN J.B., 2013. Principles and Applications of Remote Sensing. Wuhan: Wuhan University Press, pp. 105-116.

VOGELMANN J E, KOST J R, TOLK B, et al., 2011. Monitoring Landscape Change for LANDFIRE Using Multitemporal Satellite Imagery and Ancillary Data. IEEE Journal of Selected Topics in Applied Earth Observations and Remote Sensing, 4 (2), pp. 252-264. 
WANG T.Y., ZHANG G., LI D.R., et al., 2014. Comparison Images between Plane and Stereo Block Adjustment for ZY-3 Satellite. Acta Geodaetica et Cartographica Sinica, 43 (4), pp. 389-395.

WU B., GONG D.J., 2004. Highway engineering graphics files and document information management system. Journal of Chang'an University (Natural Science Edition), 24 (4), pp. $31-$ 35 .

ZHANG Q.J., 2017. System Design and Key Technologies of the GF-3 Satellite. Acta Geodaetica et Cartographica Sinica, 03 (46), pp. 269-277.
ZHANG S.R., GU Y., ZHANG Z.L., 2008. Discussion on the application of the three-dimensional design for hydraulic engineering. Journal of Hydroelectric Engineering, 27 (3), pp. 65-70.

ZHU Q., LIN H., 2004. CyberCity Geographic Information System--Three-dimensional City Models in Virtual City Environment. Wuhan: Wuhan University Press.

ZWLINSKI ME, HENDERSON J, SMITH M, 2014. Use of Landsat5 for Change Detection at 1998 Indian and Pakistani Nuclear Test Sites. IEEE Journal of Selected Topics in Applied Earth Observations and Remote Sensing, 7 (8), pp. 3453-3460. 